\title{
Exploring Factors Associated with Alcohol and/or Substance Use During the COVID-19 Pandemic
}

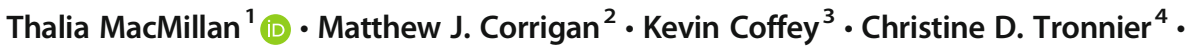 \\ Donna Wang ${ }^{4} \cdot$ Kathryn Krase ${ }^{5}$
}

Accepted: 29 December 2020 /Published online: 26 January 2021

(C) The Author(s), under exclusive licence to Springer Science+Business Media, LLC part of Springer Nature 2021

\begin{abstract}
This study explored the relationship between alcohol and substance use in the general population during the early stages of COVID-19 as related to individual, family, and community stressors. A convenience sample of adults who resided in the USA and Canada was utilized. An online survey was conducted. Over one-third of the sample reported utilizing alcohol and substances as a means to cope during the pandemic. A linear regression revealed that use of social media as a source of information, being personally affected by COVID-19, experiencing child care challenges, and not being associated with a religious community were related to increased likeliness for alcohol and/or substance use. Future research should explore these concepts further within the general population.
\end{abstract}

Keywords Coping $\cdot$ COVID-19 $\cdot$ General population $\cdot$ Stressors $\cdot$ Substance use $\cdot$ Social media

The COVID-19 pandemic seriously impacted individuals, families, and communities worldwide. Individual reactions to the pandemic are comparable to a traumatic event, disaster, or

\author{
Thalia MacMillan \\ thalia.macmillan@esc.edu \\ Matthew J. Corrigan \\ matthew.corrigan@shu.edu \\ Kevin Coffey \\ Kevin.coffey@esc.edu \\ Christine D. Tronnier \\ ctronnier@springfieldcollege.edu \\ Donna Wang \\ Dr.donnawang@gmail.com \\ Kathryn Krase \\ Kathryn.krase@yu.edu
}

Extended author information available on the last page of the article 
war (Galea et al., 2020; McLaren et al., 2020), with positive and negative forms of coping emerging in everyday life. A trend of increased alcohol and/or substance use during the COVID-19 pandemic has been identified (Ornell et al. 2020). In particular, alcohol sales have been on the rise since March 2020 (Martin 2020).

In their lifetime, 8 out of 10 adults have utilized alcohol at some point, compared to 5 out of 10 adults who have utilized illicit drugs (NIDA 2019). Research has demonstrated that use of substances and alcohol may represent a negative form of coping (Lagisetty et al. 2017; Ornell et al. 2020; Schulte and Hser 2014). In particular, increased alcohol and/or substance use is related to disasters (Bonanno et al. 2007; Galea et al. 2020), exposure to violence (Hotton et al. 2019, Rougemont-Bücking et al. 2017), and traumatic events (Berenz et al. 2016; Hansen et al. 2020; Moller et al. 2013; North et al. 2002; Read et al. 2014; Sheerin et al. 2016; Walker et al. 2020; Williams et al. 2015). However, increased alcohol and/or substance use may only represent an acute solution and not represent a long-term coping solution (SAMSHA 2020). Generalized stress, behavioral stressors, or feeling overwhelmed are also related to increased alcohol and/or substance use (Bränström and Pachankis 2018; Hassel et al. 2013; Lin et al. 2020; Sola et al. 2019). As noted by Wand et al. (2020), feeling overwhelmed may also be representative or symptomatic of several different types of mental health issues, such as depression, anxiety, or suicidal ideation. Hence, it may be worth exploring how feeling overwhelmed is related to alcohol and/or substance use during a pandemic in a non-clinical population.

Other types of stressors may also be related to alcohol and/or substance use. Daily stressors such as comorbid health conditions, lack of access to medical care, employment, and finances have been found to be related to use of substances and alcohol (Ford 2014; Moller et al. 2013; Neupert et al. 2017). Family related stressors have also been linked to alcohol and/or substance use, such as the presence of children in the home and/or concerns about childcare (Chan and Trant 2018; Rougemont-Bücking et al. 2017).

Social media has the potential to connect individuals with others, disseminate news, or inform users about current or upcoming trends (Vel et al. 2015). In its various forms, social media also has the potential to be invasive and overwhelming due to constant coverage of events and the asynchronous nature of communication (Banerjee 2020; Vel et al. 2015; Wiederhold 2020). In addition, information conveyed via social media also has the potential to amplify and spread anxiety through emotional contagion during crises or mass traumas (Goodwin et al. 2018), which is one way it may differ from traditional media coverage.

Numerous studies examining the relationship between traditional media exposure and increased psychological distress have found links between the two. For example, increased exposure to traumatic television content via the media has been linked with anxiety among Israeli respondents (Bodas et al. 2015) and among Chinese adolescents 6 months after an earthquake in Sichuan (Yeung et al. 2018). More recently, however, attention has turned to evaluating the relationship of social media use on mental health and well-being of users within the general population during crises.

Comparing individuals who followed the coverage of Hurricane Sandy via traditional media sources to those who followed the same event through social media accounts, Goodwin et al. (2013) found that stress responses were significantly higher in those who learned about the hurricane primarily through social media. Researchers suggest that these findings may reflect the extent to which emotional contagion promotes the spread of anxiety via different forms of social media (Goodwin et al. 2013). Similar research was conducted to evaluate the impact of social media use on sleep difficulties among Parisians following the 2015 Paris terrorist attacks. Social media use (i.e., 
Facebook, Twitter, and Youtube) was found to have a significant association with increases in insomnia among study participants (Goodwin et al. 2018).

While these studies did not explore users' means of coping with the increased symptoms of anxiety and insomnia, the findings do suggest that additional exploration about the impact of social media use during crises is warranted (SAMHSA 2020), as well as the fact that individuals with insomnia are known to be at increased risk for substance misuse (NIDA 2020). In addition, while other research has documented the relationship between alcohol and/or substance use and use of social media (Erevik et al. 2020; Lyers et al. 2020), little is known about the relationship between social media and negative coping — for example, via alcohol or other substance use - during a global pandemic, particularly within the general population (Wiederhold 2020).

In addition to exploring the potential use of alcohol and other substances as a means of coping, the factors that might prevent such use also warrant exploration. Individuals who are active in religion are less likely to utilize alcohol and other substances (Lo et al. 2012). Arthur et al. (2002) identified religiosity as one of the factors protecting adolescents from substance use and other negative outcomes in their Communities That Care framework. Hence, it may be worthwhile to further examine the role of religiosity in relation to the use of alcohol and other substances.

One limitation of previous research about alcohol and/or substance use is that it has primarily focused on clinical samples, individuals with a defined disorder, or a specialized sample (e.g., people convicted of a crime, college students); general community samples are needed to determine ways in which alcohol and substances are utilized as a means to cope. The purpose of this study was to examine behavioral adaptation and coping through the utilization of alcohol and/or substances during the COVID-19 pandemic by adults in the USA and Canada. More specifically, this study seeks to explore the association of behavioral stressors, general stressors, social media, and religious affiliation with the use of alcohol and/or substances in the general population.

\section{Methods}

This study involved an anonymous, cross sectional survey administered online through Qualtrics Survey Software. Institutional Review Board approval was secured prior to survey distribution. As noted by Wang et al. (2021), data were collected in June 2020 and targeted adults living in Canada and the United States (US). Informed consent was provided in the introduction of the survey, and completion of the survey was considered consent for participation. The survey was completely anonymous as no personal identifiers, including names, email addresses, and/or IP addresses, were captured for any individuals. Survey completion took about 10 min or less.

Participants were recruited through convenience and snowball sampling, utilizing researchers' personal contacts, social media, and personal and professional networks. There were additional efforts made to reach underrepresented populations and geographic areas by inviting known contacts from those communities to share the survey.

The survey consisted of thirty researcher-constructed items using a six-point Likert-type scale. The items asked respondents to indicate their level of agreement to statements concerning the COVID-19 outbreak ( 1 = strongly disagree, 6 = strongly agree): "I felt overwhelmed by the amount of information available about the Covid-19 outbreak"; "I was personally affected by the virus itself (e.g., personal contracted the virus, knowing people who have died, knowing many people in my community affected), "I experienced challenges related to medical care during the COVID-19 outbreak - medical care"; "I experienced 
challenges related to medical care during the COVID-19 outbreak - childcare"; "I experienced challenges related to medical care during the COVID-19 outbreak - financial"; "I used the following as a source of information on the COVID-19 outbreak - Social media"; "I felt prepared for the COVID-19 outbreak"; and "The following were a source of support to me during the COVID-19 outbreak - Religious Community". The main dependent variable was the response to "The following were a source of support to me during the Covid-19 outbreak: Alcohol and substances".

Respondents were also asked to provide various demographic including age, gender identity, race and ethnicity, political ideology identification, educational attainment, number of children living in the home, age categories of children living in the home, number of adults living in the home, state/province, and their geographic setting.

\section{Results}

A total of 1405 people from Canada and the USA responded to this survey. Representation from all fifty states, District of Columbia, and English-speaking Canada (all ten provinces except Quebec) was obtained. The vast majority of the sample identified as female (82.6\%), and White $(77.9 \%)$. The largest groups of the sample identified as having moderately liberal political views $(40.2 \%)$, and having a Master's degree as their highest level of education $(33.3 \%)$. The average number of children of respondents was $1.68(\mathrm{SD}=1.68$; range from 0 to 6 ), and the average age of respondents was $43.04(\mathrm{SD}=24.09$; range 18 to 86$)$. Table 1 displays the full demographics of the sample.

Over one-third of the sample reported utilizing alcohol and/or substances as a source of support $(n=415,37.5 \%)$. On average, individuals were more likely to report utilizing social media as a source of information and felt overwhelmed by the amount of information available. Bivariate analyses of the alcohol and/or substance use variable was conducted across all other study variables. A regression model was built both theoretically on the existing literature and empirically with bivariate relationships.

A two-stage, hierarchical multiple regression analysis was conducted to determine the factors related to alcohol and/or substance use during the COVID crisis (See Table 2). The predictors in the final model explained $8.5 \%$ of the variance in the level of agreement with the statement about alcohol and/or substance use. A total of eight factors (i.e., felt prepared for the COVID-19 outbreak, used social media as a source of information, personally affected by the virus, experienced medical care challenges during COVID, experienced childcare challenges during COVID, experienced financial challenges during COVID, felt overwhelmed by the amount of information, religious community was a source of support) were entered into the model, with age being controlled for in the model. Four factors were significantly related to a higher level of agreement with alcohol and/or substance use (i.e., higher use of social media, affected more personally by COVID, more likely to experience childcare challenges during COVID, and less likely to be associated with a religious community) after controlling for age.

\section{Discussion}

The results of this study provide important insight as to alcohol and/or substance use as a means to cope during the early stages of the COVID-19 pandemic. The factors that contributed 
Table 1 Demographics of the sample

\begin{tabular}{|c|c|c|}
\hline Demographic & $\mathrm{N}$ & $x_{-}(\mathrm{SD}) / \%$ \\
\hline Age & & $43.04(24.09)$ \\
\hline Number of children & & $1.68(0.97)$ \\
\hline \multicolumn{3}{|l|}{ Gender identity } \\
\hline Female & 1154 & 82.6 \\
\hline Male & 227 & 16.2 \\
\hline Other & 17 & 1.21 \\
\hline \multicolumn{3}{|l|}{ Race/ethnicity* } \\
\hline American Indian/First Nations & 11 & .75 \\
\hline Asian & 41 & 2.8 \\
\hline Black or African-American & 128 & 8.7 \\
\hline Hispanic, Latino or Spanish origin & 97 & 6.6 \\
\hline Middle Eastern or North African & 17 & 1.7 \\
\hline Native Hawaiian of other Pacific Islander & 6 & .41 \\
\hline White & 1138 & 77.9 \\
\hline Other & 27 & 1.8 \\
\hline \multicolumn{3}{|l|}{ Education } \\
\hline Less than HS diploma & 1 & .07 \\
\hline HS diploma or GED & 316 & 22.6 \\
\hline Associate's degree & 100 & 7.2 \\
\hline Bachelor's degree & 320 & 22.9 \\
\hline Master's degree & 466 & 33.3 \\
\hline Doctoral degree or $\mathrm{PhD}$ & 195 & 14.0 \\
\hline I felt prepared for the COVID-19 outbreak & & $2.50(1.59)$ \\
\hline Used social media as a source of information & & $4.53(1.60)$ \\
\hline I was personally affected by the virus itself & & $3.37(1.94)$ \\
\hline Experienced childcare challenges & & $3.46(1.87)$ \\
\hline Experienced medical care challenges & & $2.89(2.19)$ \\
\hline Experienced financial challenges & & $3.38(1.91)$ \\
\hline I felt overwhelmed by the amount of information available & & $4.17(1.61)$ \\
\hline Religious community was a source of support to me & & $3.51(1.88)$ \\
\hline Alcohol and substances were a source of support to me & & $2.55(1.71)$ \\
\hline
\end{tabular}

*More than one option could be selected

Table 2 Hierarchical regression analysis of predictors of adapting/coping well to COVID

\begin{tabular}{llr}
\hline Predictors & Model 1 & $\begin{array}{c}\text { Model } 2 \\
\beta\end{array}$ \\
\hline Age & $\beta$ & .04 \\
Felt prepared & -.01 & -.06 \\
Information source & & $.14^{* *}$ \\
$\quad$ Social Media & & $.11^{*}$ \\
Personally affected & & -.08 \\
Challenges in crisis & & $.16^{* *}$ \\
Medical Care & & -.01 \\
Childcare & & -.18 \\
Financial & & $-.15^{* * *}$ \\
Overwhelmed by info & .002 & $.085^{* * *}$ \\
Source of support & & $.083^{* * *}$ \\
Religious community & & \\
$R^{2}$ & & \\
$R^{2}$ change & & \\
\hline
\end{tabular}

$n=1075, * p<0.05, * * p=<0.005$ 
to higher reported alcohol and/or substance use were higher use of social media as a source of information, affected more personally by COVID, more likely to experience childcare challenges during COVID, and less likely to be associated with a religious community.

Over one-third of the sample agreed that they utilized alcohol and/or substances as way to cope with the COVID-19 pandemic. This is similar to the results found by Ornell et al. (2020) and Panagiotidis et al. (2020) that alcohol and substances are being utilized during the COVID-19 pandemic as a possible means to cope. As this may represent a negative form of coping (Lagisetty et al. 2017; Ornell et al. 2020; Schulte and Hser 2014), this may be worth exploring further by determining frequency and amount of alcohol and/or substances being utilized. As the regression only explained $8.5 \%$ of the variance for alcohol and/or substance use, this suggests that what we know of use during the pandemic is multi-dimensional and multi-faceted. As the majority of the sample was female, it would be interesting to examine the results in greater detail as it may impact use and the factors that are related to it.

Higher utilization of social media was related to higher alcohol and/or substance use. These findings are consistent with previous research that has examined a definitive diagnosis of a substance use disorder with use of social media (Erevik et al. 2020; Lyers et al. 2020). Moreno et al. (2016) noted that social media conveys messages about the acceptability regarding the types and amount of alcohol and/or substance use that may be acceptable. Similar to Wiederhold (2020), this study seeks to explore alcohol and substances as a means to cope, but within the content of the general population. Future research could examine the frequency and amount of past and present use, as well as types of alcohol and/or substances. Additionally, the social media platform, the type of content being viewed, and quantity of its use should also be explored in greater depth. Previous research has explored the potential for social media platforms to amplify and spread emotional contagion during crises (Goodwin et al. 2018), thereby increasing emotional distress among users. It is possible that information about the pandemic was also garnered from social media; hence, higher social media usage may equate to more information gathered, potentially leading to alcohol and/or substance use as a means of coping with the information overload or increased anxiety resulting from emotional contagion.

Personal and family stressors were also found to be related to use of alcohol and substances in this sample. Being personally affected by COVID-19 and being concerned about child care were found to be related to increase use of alcohol and substances. Being personally affected may be symbolic of trauma, complicated grief, or represent a generalized stressor; all of which are related to alcohol and/or substance use (Berenz et al. 2016; Bränström and Pachankis 2018; Hansen et al. 2020; Hassel et al. 2013; Lin et al. 2020; Moller et al. 2013; North et al. 2002; Read et al. 2014; Sola et al. 2019; Sheerin et al. 2016; Walker et al. 2020; Williams et al. 2015). This relationship should be examined further to determine how being affected personally, such as individually being diagnosed with COVID, being at high risk for COVID, or knowing others who are at risk or who have been diagnosed, is related to use of alcohol and substances. It could be posited that this represents a multidimensional concept that a single-item question only briefly measures.

Other types of stressors may also be related to alcohol and/or substance use. Daily stressors such as health, access to medical care, employment, and finances have been found to be related to use of substances and alcohol (Ford 2014; Moller et al. 2013; Neupert et al. 2017). Family-related stressors have also been linked to alcohol and/or substance use, such as the presence of children in the home and/or concerns about access to childcare (Chan and Trant 2018; Rougemont-Bücking et al. 2017). Finally, individuals who did not belong to a religious community were more likely to utilize alcohol and drugs. Combined together, these stressors highlight that individual, family, and/or community factors may be related to the use of alcohol and other substances in the general population. 


\section{Limitations}

This study utilized a convenience sample. Although this limits the degree to which the findings can be generalized, it represents an opportunity to examine alcohol and/or substance use in the community, unlike previous samples that have mainly utilized clinical samples or specific groups. Research has only begun to explore alcohol and/or substance use in the general population during the pandemic; perhaps this study contributes to knowledge base about this critical concern. Also, as the majority of the sample was female, it is possible that the stigma regarding women and substance use might have impacted the responses. This represents an area that should be explored further.

Only single-item measures were utilized for each variable. Thus the frequency of use and type of substance use is unknown. The item to assess alcohol and/or substance use may be subject to selfreport bias by individuals in the survey as no formal definition was provided. Additionally, our design precluded the ability to assess change in use due to COVID-19, or if individuals' substance use remained constant before and during COVID-19. While this may be seen as limiting, it does allow for the exploration of several different concepts. The results of the study represent an exploration of many areas, and highlight concepts should be examined further. However, what we do know from this study is that a certain segment of the sample uses substances for coping, which helps inform maladaptive coping during stressors. This type of measurement is also representative of what many practitioners may utilize as a form of screening to determine potential issues or risk factors.

Limited demographic data was available for each individual. Marital status was not assessed in the study, nor was the total amount of individuals living within the home or having children (regardless of presence within the home). Personal data about the individual is also not captured, such as a mental health diagnosis (e.g., depression or anxiety). Each of these factors may represent additional stress factors that should be taken into account when examining alcohol and/or substance use.

Finally, the study did include individuals from the USA and Canada as part of the sample. We recognize that both countries have responded to COVID-19 in different ways. However, the pandemic is a worldwide phenomenon, and regardless of location, individuals are resourcing information and reacting to it within their own personal way. Future studies should explore the differences between residents of the USA and Canada for their utilization of alcohol and substances.

\section{Implications for Practice}

Overall, the findings from this study suggest that there is a need to assess use of alcohol and substances in all populations, particularly those not in a clinical setting. Use of alcohol and substances may represent a negative form of coping; the impact of personal or family stressors and/or a traumatic experience, such as the pandemic, may cause some individuals to utilize substances more than others. Practitioners are encouraged to assess who is at risk, especially those who have personal or family stressors.

However, one limitation is the potential decrease in accessibility of assessment and referral caused by the pandemic and subsequent shutdowns. SAMHSA has funded the development of the Screening, Brief Intervention, and Referral to Treatment (SBIRT) assessment protocol, intended to universally screen for substance use issues (Inman et al. 2020; Levy et al. 2020). This model has largely been employed in medical settings, such as primary care and emergency rooms, in an effort 
to capture as many people as possible (Davoudi and Rawson 2010). Not only has the pandemic limited the face to face availability of these outlets, the accompanying economic fallout has resulted in many losing employment, and therefore their medical insurance, in the USA. Thus, as use of substances as a coping mechanism has risen, the safeguard of universal screening for problems has become more limited. An area of focus for practice will be to train clinicians in the use of SBIRT online while identifying additional avenues for universal implementation, perhaps through the use of social media. Boudreaux et al. (2015) demonstrated the potential in such practice. In addition, as has been suggested by Goodwin et al. (2018) previously, public health officials and clinicians might consider creating anxiety-mediating interventions that target social media users during times of crises, such as the COVID-19 pandemic, in an effort to curtail the spread of emotional contagion and/or to promote healthy coping among social media users.

Overall, this study was able to demonstrate that the general population is utilizing alcohol and substances, potentially as a means of coping with the pandemic. External stressors, such as the use of social media, and internal stressors, such as being personally affected, were related to use. This topic deems further exploration to determine magnitude and depth of use, as well as exploring other factors related to alcohol and/or substance use during the pandemic.

\section{Compliance with Ethical Standards}

Conflict of Interest The authors reported no conflicts of interest.

Ethical Approval The current study was designed in accordance with the Policy Statement on Ethical Conduct for Research Involving humans and approved by the SUNY Empire State College Institutional Review Board.

\section{References}

Arthur, M. W., Hawkins, J. D., Pollard, J. A., Catalano, R. F., \& Baglioni, A. J. (2002). Measuring risk and protective factors for substance abuse, delinquency, and other adolescent problem behaviors: The communities that care youth survey. Evaluation Review, 26(6), 575-601.

Banerjee, D. (2020). How COVID-19 is overwhelming our mental health. Nature India [online journal].

Berenz, E. C., Kevorkian, S., Chowdhury, N., Dick, D. M., Kendler, K. S., \& Amstadter, A. B. (2016). Posttraumatic stress disorder symptoms, anxiety sensitivity, and alcohol-use motives in college students with a history of interpersonal trauma. Psychology of Addictive Behaviors, 30(7), 755-763 https://doi-org. library.esc.edu/10.1037/adb0000193.

Bodas, M., Siman-Tov, M., Peleg, K., \& Solomon, Z. (2015). Anxiety-inducing media: The effect of constant news broadcasting on the well-being of Israeli television viewers. Psychiatry: Interpersonal \& Biological Processes, 78(3), 265-276 https://doi-org.libproxy.smith.edu/10.1080/00332747.2015.1069658.

Bonanno, G. A., Galea, S., Bucciarelli, A., \& Vlahov, D. (2007). What predicts psychological resilience after disaster? The role of demographics, resources, and life stress. Journal of Consulting and Clinical Psychology, 75(5), 671-682.

Boudreaux, E. D., Haskins, B., Harralson, T., \& Bernstein, E. (2015). The remote brief intervention and referral to treatment model: Development, functionality, acceptability, and feasibility. Drug and Alcohol Dependence, 155, 236-242.

Bränström, R., \& Pachankis, J. E. (2018). Sexual orientation disparities in the co-occurrence of substance use and psychological distress: A national population-based study (2008-2015). Social Psychiatry and Psychiatric Epidemiology: The International Journal for Research in Social and Genetic Epidemiology and Mental Health Services, 53(4), 403-412. https://doi.org/10.1007/s00127-018-1491-4.

Chan, K. T., \& Trant, J. (2018). The relationship of psychological distress and living with children and adolescents for adult non-medical prescription opioid users. Child \& Adolescent Social Work Journal, 35(4), 391-405. 
Davoudi, M., \& Rawson, R. A. (2010). Screening, brief intervention, and referral to treatment (SBIRT) initiatives in California: Notable trends, challenges, and recommendations. Journal of Psychoactive Drugs, 6(2), 239-248.

Erevik, E.K., Pallesen, S., Vedaa, O., Andreassen, C.S., Dhir, A., \& Torsheim, T. (2020). General and alcoholrelated social media use and mental health: A large-sample longitudinal study. International Journal of Mental Health and Addiction [online journal].

Ford, J. (2014). Poor health, strain, and substance use. Deviant Behavior, 35(8), 654-667.

Galea, S., Merchant, R. M., \& Lurie, N. (2020). The mental health consequences of COVID-19 and physical distancing: The need for prevention and early intervention. JAMA Internal Medicine, 180(6), 817-818. https://doi.org/10.1001/jamainternmed.2020.1562.

Goodwin, R., Palgi, Y., Hamama-Raz, Y., \& Ben-Ezra, M. (2013). In the eye of the storm or the Bullseye of the media: Social media use during Hurricane Sandy as a predictor of post- traumatic stress. Journal of Psychiatric Research, 47(8), 1099-1100 https://doi-org.libproxy.smith.edu/10.1016/j.jpsychires.2013.04.006.

Goodwin, R., Lemola, S., \& Ben-Ezra, M. (2018). Media use and insomnia after terror attacks in France. Journal of Psychiatric Research, 98, 47-50 https://doi-org.libproxy.smith.edu/10.1016/j.jpsychires.2017.12.006.

Hansen, M. C., Ghafoori, B., \& Diaz, M. (2020). Examining attitudes towards mental health treatment and experiences with trauma: Understanding the needs of trauma-exposed middle-aged and older adults. Journal of Community Psychology, 48(5), 1452-1468.

Hassel, A., Nordfjaern, T., \& Hagen, R. (2013). Psychological and interpersonal distress among patients with substance use disorders: Are these factors associated with continued drug use and do they change during treatment. Journal of Substance Use, 18(5), 363-376.

Hotton, A., Quinn, K., Schneider, J., \& Voisin, D. (2019). Exposure to community violence and substance use among Black men who have sex with men: Examining the role of psychological distress and criminal justice involvement. AIDS Care, 31(3), 370-378.

Inman, D., El-Mallakh, P., Jensen, L., Ossege, J., \& Scott, L. (2020). Addressing substance use in adolescents: Screening, brief intervention, and referral to treatment. The Journal for Nurse Practitioners, 16(1), 69-73.

Lagisetty, P. A., Maust, D., Heisler, M., \& Bohnert, A. (2017). Physical and mental health comorbidities associated with primary care visits for substance use disorders. Journal of Addictive Medicine, 11(2), 161-162.

Levy, S., Wiseblatt, A., Straus, J. H., Strother, H., Fluet, C., \& Harris, S. (2020). Adolescent SBIRT practices among pediatricians in Massachusetts. Journal of Addiction Medicine, 14(2), 145-149.

Lin, S. Y., Fried, E. I., \& Eaton, N. R. (2020). The association of life stress with substance use symptoms: A network analysis and replication. Journal of Abnormal Psychology, 129(2), 204-214.

Lo, C., Tenorio, K. A., \& Cheng, T. C. (2012). Racial differences in co-occurring substance use and serious psychological distress: The roles of marriage and religiosity. Substance Use \& Misuse, 47(6), 734-744.

Lyers, M., Cutinho, D., \& Thorberg, F. A. (2020). Alexithymia, impulsivity, disordered social media use, mood and alcohol use in relation to Facebook self-disclosure. Computers in Human Behavior, 103, 174-180.

Martin, K. (2020). Impact of COVID-19 on retail alcohol sales. Found on the World Wide Web: https://www. winsightgrocerybusiness.com/center-store/impact-covid-19-retail-alcohol-sales

McLaren, H. J., Wong, K. R., Nguyen, K. N., \& Mahamadachchi, K. N. D. (2020). COVID-19 and women's triple burden: Vignettes from Sri Lanka, Malaysia, Vietnam and Australia. Social Sciences, 9(5), 87. https:// doi.org/10.3390/socsci9050087.

Moller, C. I., Tait, R. J., \& Byrne, D. G. (2013). Self-harm, substance use, and psychological distress in the Australian general population. Addiction, 108(1), 211-220.

Moreno, M. A., D’Angelo, J., \& Whitehill, J. (2016). Social media and alcohol: Summary of research, intervention ideas and future study directions. Adolescents in the Digital Age, 4(3) [online journal].

National Institute of Drug Abuse (NIDA) (2019). National survey on drug use and health: Trends in prevalence of various drugs for ages 12 or older, ages 12 to 17, ages 18 to 25, and ages 26 or older; 2016-2018 (in percent). As found on the World Wide Web: https://www.drugabuse.gov/drug-topics/trends-statistics/ national-drug-early-warning-system-ndews/national-survey-drug-use-health.

National Institute of Drug Abuse (NIDA) (2020). Connections between sleep and substance use disorders. Retrieved from https://www.drugabuse.giv/about-nida/noras-blog/2020/03/connections-between-sleepsubstance-use-disorders on 2020, November 27.

Neupert, S. D., Desmarais, S. L., Gray, J. S., Cohn, A. M., Doherty, S., \& Knight, K. (2017). Daily stressors as antecedents, correlates, and consequences of alcohol and drug use and cravings in community-based offenders. Psychology of Addictive Behaviors, 31(3), 315-325.

North, C. S., Tivis, L., Mcmillen, J. C., Pfefferbaum, B., Cox, J., Spitznagel, E. L., et al. (2002). Coping, functioning, and adjustment of rescue workers after the Oklahoma City bombing. Journal of Traumatic Stress, 15(3), 171-175. https://doi.org/10.1023/a:1015286909111.

Ornell, F., Ferreira Moura, H., Nichterwitz Scherer, J., Pechansky, F., Kessler, F. H. P., \& von Diemen, L. (2020). The COVID-19 pandemic and its impact on substance use: Implications for prevention and treatment. Psychiatry Research, 289, 113096. 
Panagiotidis, P., Rantis, K., Holeva, V., Parlapani, E., \& Diakogiannis, I. (2020). Changes in alcohol use habits in the general population, during the COVID-19 lockdown in Greece. Alcohol and alcoholism (Oxford, Oxfordshire), 55(6), 702-704. https://doi.org/10.1093/alcalc/agaa092.

Read, J. P., Griffin, M. J., Wardell, J. D., \& Ouimette, P. (2014). Coping, PTSD symptoms, and alcohol involvement in trauma-exposed college students in the first three years of college. Psychology of Addictive Behaviors, 28(4), 1052-1064.

Rougemont-Bücking, A., Grazioli, V. S., Daeppen, J. B., Gmel, G., \& Studer, J. (2017). Family-related stress versus external stressors: Differential impacts on alcohol and illicit drug use in young men. European Addiction Research, 23(6), 284-297.

Schulte, M. T., \& Hser, Y. I. (2014). Substance use and associated health conditions throughout the lifespan. Public Health Reviews, 35(2), 1-23.

Sheerin, C., Berenz, E. C., Knudsen, G. P., Reichborn-Kjennerud, T., Kendler, K. S., Aggen, S. H., \& Amstadter, A. B. (2016). A population-based study of help seeking and self-medication among trauma-exposed individuals. Psychology of Addictive Behaviors, 30(7), 771-777.

Sola, V., Sakiyama, H. M. T., Rato Padin, M. D. F., Canfield, M., Bortolon, C. B., Laranjeira, R., \& Mitsuhiro, S. S. (2019). Measuring stress, coping, strain, and hopefulness of Brazilian family members of substance misusers: Factor structure of a set of measures. Journal of Substance Use, 24(2), 130-139.

Substance Abuse and Mental Health Services Administration (SAMHSA) (2020). Substance use disorder treatment for people with co-occurring disorders. U.S. Department of Health and Human Services, https:// store.samhsa.gov/product/tip-42-substance-use-treatment-persons-co-occurring-disorders/PEP20-02-01-004

Vel, K., Brobbey, C., Salih, A., \& Jaheer, H. (2015). Data, technology \& social media: Their invasive role in contemporary marketing. Revista Brasileira De Marketing E-ISSN, 14(4), 2177-5184.

Walker, D. D., Jaffe, A. E., Pierce, A. R., Walton, T. O., \& Kaysen, D. L. (2020). Discussing substance use with clients during the COVID-19 pandemic: A motivational interviewing approach. Psychological Trauma Theory Research Practice and Policy, 12(S1), S115-S117.

Wand, A., Zhong, B., Chiu, H., Draper, B., \& De Leo, D. (2020). COVID-19: The implications for suicide in older adults. International Psychogeriatrics, 1-6.

Wang, D., Marmo, S., Krase, K., \& Phanod, L. (2021). Compliance with preventative measures during the COVID-19 pandemic in the USA and Canada: Results from an online survey. (in press.)

Wiederhold, B. K. (2020). Social media use during social distancing. Cyberpsychology, Behavior and Social Networking, 23(5), 275-276.

Williams, E. C., Frasco, M. A., Jacobson, I. G., Maynard, C., Littman, A. J., Seelig, A. D., Crum-Cianflone, N. F., Nagel, A., \& Boyko, E. J. (2015). Risk factors for relapse to problem drinking among current and former US military personnel: A prospective study of the Millennium Cohort. Drug and Alcohol Dependence, 148, 93-101.

Yeung, N. C. Y., Lau, J. T. F., Yu, N. X., Zhang, J., Xu, Z., Choi, K. C., Zhang, Q., Mak, W. W. S., \& Lui, W. W. S. (2018). Media exposure related to the 2008 Sichuan earthquake predicted probable PTSD among Chinese adolescents in Kunming, China: A longitudinal study. Psychological Trauma Theory Research Practice and Policy, 10(2), 253-262 https://doi-org.libproxy.smith.edu/10.1037/tra0000121.

Publisher's Note Springer Nature remains neutral with regard to jurisdictional claims in published maps and institutional affiliations.

\section{Affiliations}

\section{Thalia MacMillan ${ }^{1} \cdot$ Matthew J. Corrigan ${ }^{2} \cdot$ Kevin Coffey $^{3} \cdot$ Christine D. Tronnier $^{4}$. Donna Wang ${ }^{4} \cdot$ Kathryn Krase ${ }^{5}$}

\footnotetext{
1 Department Chair, SUNY Empire State College, Saratoga Springs, NY, USA

2 MSW Program, Seton Hall University, South Orange, NJ, USA

3 SUNY Empire State College, Saratoga Springs, NY, USA

4 Springfield College, Springfield, MA, USA

5 Yeshiva University, New York, NY, USA
} 